\title{
Silane- and triazine-containing hole and exciton blocking material for high-efficiency phosphorescent organic light emitting diodes $\dagger$
}

\author{
Jae-Wook Kang, $\dagger^{a}$ Deug-Sang Lee, ${ }^{b}$ Hyung-Dol Park, ${ }^{a}$ Young-Seo Park, ${ }^{a}$ Ji Whan Kim, ${ }^{a}$ Won-Ik Jeong, ${ }^{a}$ \\ Kyung-Mo Yoo, ${ }^{a}$ Kyoungmoon Go, ${ }^{b}$ Se-Hoon Kim ${ }^{b}$ and Jang-Joo Kim*a
}

\author{
Received 16th April 2007, Accepted 20th June 2007 \\ First published as an Advance Article on the web 5th July 2007 \\ DOI: $10.1039 / \mathrm{b} 705741 \mathrm{e}$
}

\begin{abstract}
One of the important factors for high efficiency phosphorescent organic light-emitting devices is to confine triplet excitons within the emitting layer. We synthesized and characterized a new hole blocking material containing silane and triazine moieties, 2,4-diphenyl-6-(4'-triphenylsilanylbiphenyl-4-yl)-1,3,5-triazine (DTBT). Electrophosphorescent devices fabricated using the material as the hole-blocking layer and $N, N^{\prime}$-dicarbazolyl-4,4'-biphenyl (CBP) doped with fac-tris(2phenylpyridine)iridium $\left[\operatorname{Ir}(\mathrm{ppy})_{3}\right]$ as the emitting layer showed a maximum external quantum efficiency $\left(\eta_{\text {ext }}\right)$ of $17.5 \%$ with a maximum power efficiency $\left(\eta_{\mathrm{p}}\right)$ of $47.8 \mathrm{~lm} \mathrm{~W} \mathrm{~m}^{-1}$, which are much

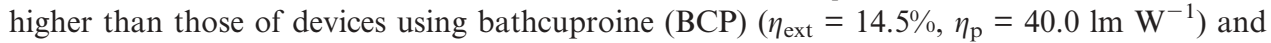
4-biphenyloxolate aluminium(III) bis(2-methyl-8-quinolinato)-4-phenylphenolate (BAlq) $\left(\eta_{\text {ext }}=\right.$ $8.1 \%, \eta_{\mathrm{p}}=14.2 \mathrm{~lm} \mathrm{~W}^{-1}$ ) as hole-blocking layers.
\end{abstract}

\section{Introduction}

Utilization of phosphorescent dyes as the light emitting material in organic light emitting diodes (OLEDs) requires efficient hole and exciton blocking layers. Baldo et al. ${ }^{1}$ reported efficient green emission from fac-tris(2-phenylpyridine)iridium $\left[\operatorname{Ir}(\mathrm{ppy})_{3}\right]$ doped in $N, N^{\prime}$-dicarbazolyl-4,4'-biphenyl (CBP) with a maximum quantum efficiency of $8 \%$. If the bathcuproine (BCP) layer was omitted from the device, the efficiency dropped dramatically, to only $0.2 \%$. The BCP layer blocks excitons and also prevents holes from migrating from the doped CBP layer into the electron transfer layer. For a material to be an efficient hole blocker, it must have a highest occupied molecular orbital (HOMO) level deeper than that of the dopant or host material, and the triplet energy must be high enough to efficiently prevent triplet excitons from migrating out of the luminescent layer. ${ }^{2}$ The most common hole-blocking materials are $\mathrm{BCP}^{3-5}$ and 4-biphenyloxolate aluminium(III) bis(2-methyl-8-quinolinato)-4-phenylphenolate (BAlq) ${ }^{6,7}$ A number of other organic materials have also been used as hole-blocking materials, such as fluorinated phenylenes, ${ }^{5}$ oxidiazole and triazole containing molecules (TPBi, PBD, TAZ), ${ }^{8}$ 1,8-naphthalimides, ${ }^{9}$ polyquinolines, ${ }^{10}$ and bis(2-(4,6-difluorophenyl)pyridyl- $\left.N, C 2^{\prime}\right)$ iridium(III) picolinate (Flrpic). ${ }^{2}$

\footnotetext{
${ }^{a}$ Department of Materials Science and Engineering, and OLED Center, Seoul National University, Seoul 151-744, Korea.

E-mail: jjkim@snu.ac.kr; Fax: +82-2-880-9672; Tel: +82-2-880-7893

${ }^{b}$ Dongwoo Fine-Chem Co., LTD., Organic Synthesis Group, Pyeongtaek 451-822, Korea

$\uparrow$ Electronic supplementary information (ESI) available: Measurement of energy levels of BAlq, BCP and DTBT using cyclic voltammetry (CV). See DOI: 10.1039/b705741e

* Present address: Surface Technology Research Center, Korea Institute of Machinery \& Materials (KIMM), Changwon 641-831, Korea.
}

In this paper, we describe the design and synthesis of a novel effective hole- and exciton-blocking material, 2,4-diphenyl-6(4'-triphenylsilanyl-biphenyl-4-yl)-1,3,5-triazine (DTBT). The material has triphenylsilane and triazine moieties in the molecule. The triazine moiety was introduced to get high electron mobility and a deep HOMO level. The silane moiety is expected to provide high thermal and chemical stability and glassy properties. ${ }^{11} \operatorname{Ir}(\text { ppy })_{3}$ based OLEDs using the material as the hole-blocking layer resulted in a maximum external quantum efficiency $\left(\eta_{\text {ext }}\right)$ of $17.5 \%$ which corresponds to an internal quantum efficiency of $\sim 90 \%$ by assuming that $20 \%$ of the emitted light is extracted and a power efficiency $\left(\eta_{\mathrm{p}}\right)$ of $47.8 \mathrm{~lm} \mathrm{~W}^{-1}$.

\section{Results and discussion}

DTBT was prepared by a Suzuki-Miyaura coupling reaction of 4-triphenylsilylphenylboronic acid and 2-(4-bromophenyl)4,6-diphenyl-1,3,5-triazine introduced by the ring formation reaction of benzamidines with Schiff bases (Scheme 1). The HOMO level of the molecule measured by the cyclic voltammetry technique was $6.5 \mathrm{eV}$, which is much lower than those of commonly used BCP or BAlq (discussion on the energy levels is described in the ESI $\dagger$ ). Therefore, more efficient hole blocking is expected using this material. The electron mobility of DTBT measured by the time-of-flight technique ${ }^{12}$ was $5.3 \times 10^{-5} \mathrm{~cm}^{2} \mathrm{~V}^{-1} \mathrm{~s}^{-1}$ at an applied field of

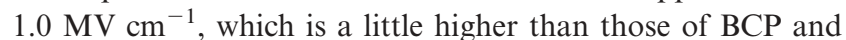
BAlq $\left(4.6 \times 10^{-5}\right.$ and $3.1 \times 10^{-5} \mathrm{~cm}^{2} \mathrm{~V}^{-1} \mathrm{~s}^{-1}$ at $1.0 \mathrm{MV} \mathrm{cm}^{-1}$, respectively). Fig. 1 shows the absorption and fluorescence spectra of DTBT solution $\left(1 \times 10^{-5} \mathrm{M}\right.$ in dichloromethane) and film, and phosphorescence spectra of DTBT films at $T=12 \mathrm{~K}$. The photoluminescence (PL) spectrum of the film showed about $40 \mathrm{~nm}$ red-shift from that of the solution and another peak at around $550 \mathrm{~nm}$. These results indicate that intermolecular interactions in the film are significant. The 


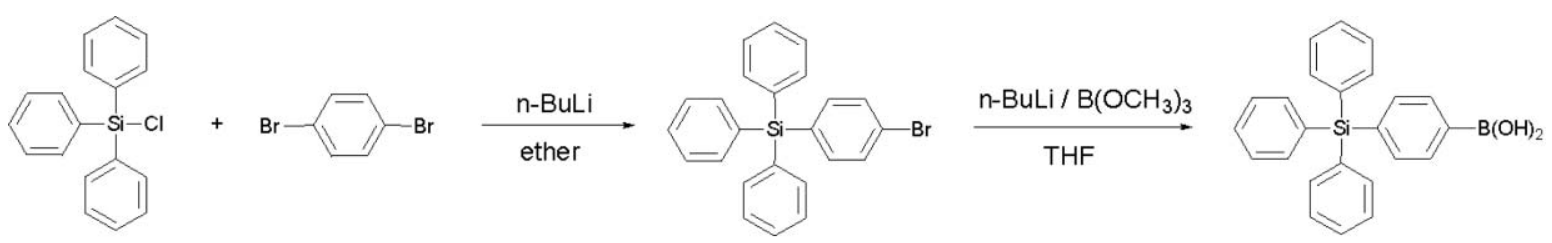

(1)

(2)
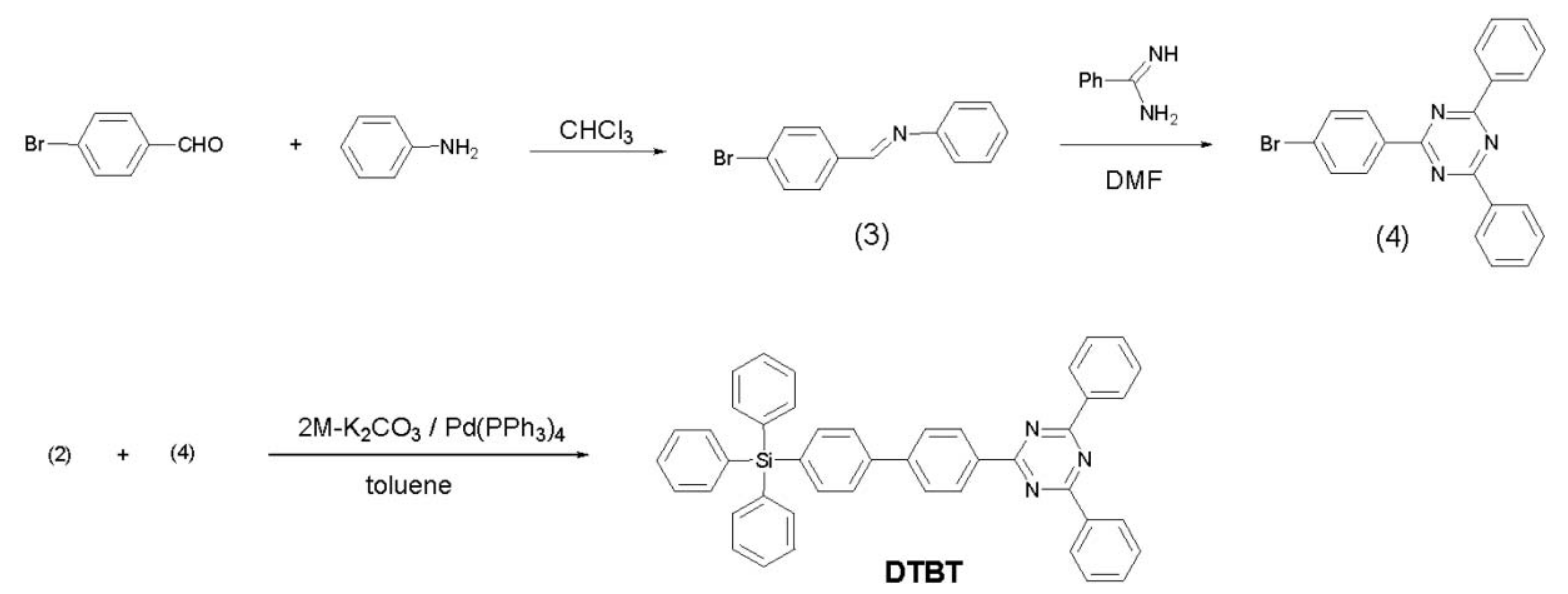

Scheme 1 Synthesis route to DTBT.

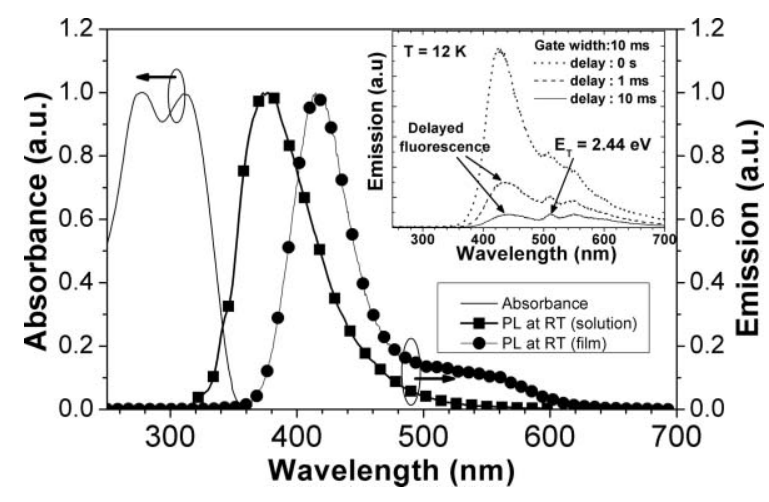

Fig. 1 Absorption and fluorescence spectra of DTBT solution and film at room temperature (RT). Inset are the phosphorescence spectra of DTBT films at $T=12 \mathrm{~K}$.

triplet energy level $\left(E_{\mathrm{T}}\right)$ of DTBT estimated from the phosphorescence peak was $2.44 \mathrm{eV}$ as shown in the inset of Fig. 1. In the spectra, delayed fluorescent (DF) was significant even though the excitation power was kept almost as low as the detection limit of the spectra. The $E_{\mathrm{T}}$ of DTBT is similar to that of green phosphorescent dopants such as $\operatorname{Ir}(\mathrm{ppy})_{3}$
$\left(E_{\mathrm{T}}=2.42-2.46 \mathrm{eV}\right) .{ }^{13}$ Physical properties of the molecule are summarized and are compared with those of BCP and BAlq in Table 1. The high HOMO level and high electron mobility combined with comparable triplet energy level of the newly synthesized molecule, DTBT, indicate that the material is expected to work as an excellent hole-blocking material.

The OLEDs were fabricated by thermal evaporation onto a cleaned glass substrate precoated with transparent, conductive indium tin oxide (ITO). Prior to organic layer deposition, ITO substrates were exposed to UV-ozone flux for $10 \mathrm{~min}$ following degreasing in acetone and isopropyl alcohol. All organic layers were grown by thermal evaporation at the base pressure of $<5 \times 10^{-8}$ Torr in the following order: hole transporting layer (HTL)/emission layer (EML)/hole blocking layer (HBL)/ electron transporting layer (ETL)/cathode. The HTL was $40 \mathrm{~nm}$ thick NPB, the EML was $30 \mathrm{~nm}$ thick CBP doped with 6 wt. $\% \operatorname{Ir}(\text { ppy })_{3}$, the HBL was $10 \mathrm{~nm}$ thick DTBT, BCP, or BAlq and the ETL was $40 \mathrm{~nm}$ thick $\mathrm{Alq}_{3}$. All the materials were train sublimated before use for purification. The cathode consisting of $1 \mathrm{~nm}$ thick $\mathrm{LiF}$ and a $100 \mathrm{~nm}$ thick layer of $\mathrm{Al}$ were deposited onto the sample surface as shown in Fig. 2.

Fig. 3 exhibits the current density-voltage-luminance $(J-V-L)$ characteristics of the phosphorescent OLEDs where

Table 1 Summary of the electrical properties and device performance

\begin{tabular}{|c|c|c|c|c|c|c|c|c|}
\hline $\begin{array}{l}\mathrm{HBL} \\
\text { materials }\end{array}$ & $\mathrm{HOMO} / \mathrm{eV}$ & LUMO/eV & $E_{\mathrm{T}} / \mathrm{eV}$ & $\begin{array}{l}\text { Electron } \\
\text { mobility }{ }^{a} / \mathrm{cm}^{2} \mathrm{~V}^{-1} \mathrm{~s}^{-1}\end{array}$ & $\begin{array}{l}\text { Peak of } \\
\eta_{\text {ext }}^{b}(\%)\end{array}$ & $\begin{array}{l}\text { Peak of } \\
\eta_{\mathrm{p}}{ }^{c} / \mathrm{lm} \mathrm{W}^{-1}\end{array}$ & $\eta_{\mathrm{ext}}{ }^{d}(\%)$ & $\eta_{\mathrm{p}}^{e} / \mathrm{lm} \mathrm{\textrm {W } ^ { - 1 }}$ \\
\hline DTBT & 6.5 & 3.0 & 2.44 & $5.3 \times 10^{-5}$ & 17.5 & 47.8 & 14.3 & 28.3 \\
\hline $\mathrm{BCP}$ & 6.1 & 2.56 & $2.50^{2}$ & $4.6 \times 10^{-5}$ & 14.5 & 40.0 & 12.2 & 25.4 \\
\hline BAlq & 5.57 & 2.58 & $2.18^{15}$ & $3.1 \times 10^{-5}$ & 8.1 & 14.2 & 7.5 & 14.0 \\
\hline
\end{tabular}

${ }^{a}$ At the applied field of $1.0 \mathrm{MV} \mathrm{cm}{ }^{-1} .{ }^{b}$ Peak of external quantum efficiency. ${ }^{c}$ Peak of power efficiency. ${ }^{d}$ External quantum efficiency at $100 \mathrm{~cd} \mathrm{~m}^{-2}$. ${ }^{e}$ Power efficiency at $100 \mathrm{~cd} \mathrm{~m}^{-2}$. 


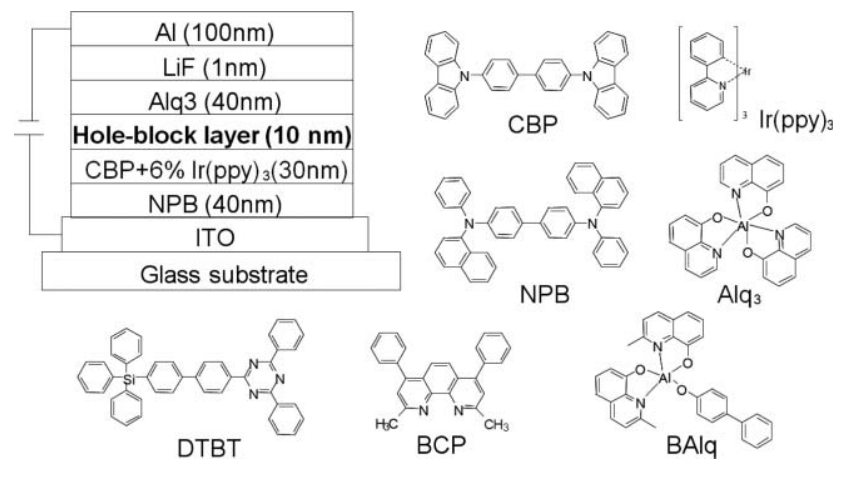

Fig. 2 The electrophosphorescent device structure and the chemical structures of the materials used in the devices.
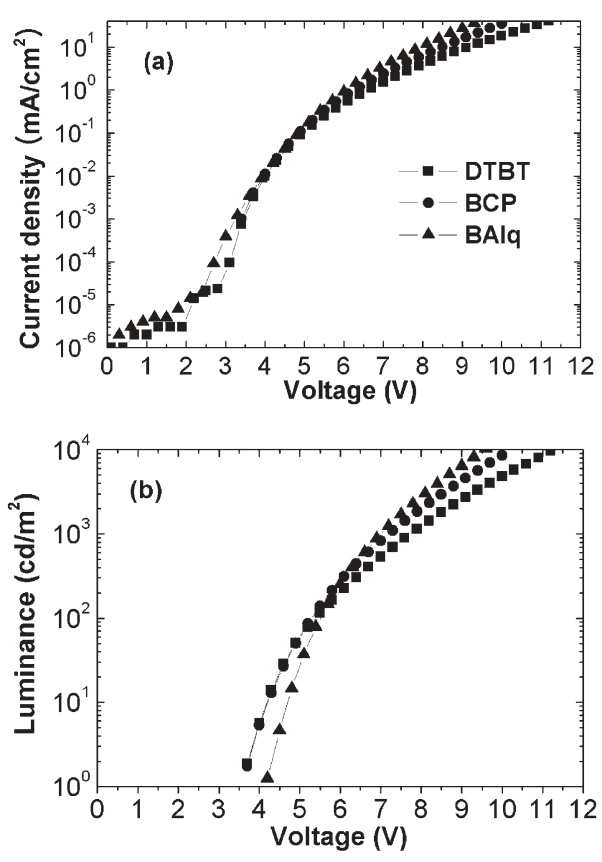

Fig. 3 (a) Current density-voltage $(J-V)$ and (b) luminescencevoltage $(L-V)$ characteristics using three different hole-blocking materials.

6 wt.\% $\operatorname{Ir}(\text { ppy })_{3}$ was doped into CBP with different HBLs. All the devices exhibit very low leakage current density before the turn-on voltage due to the absence of a shunt resistance, which is indicative of leaky interfaces between the anode/organic and cathode/organic interfaces. It is noteworthy that the $\eta_{\mathrm{ext}}$ and $\eta_{\mathrm{p}}$ with a DTBT HBL are much higher than those with BCP and BAlq as shown in Fig. 4 and summarized in Table 1. When we employ DTBT as a HBL, the $\eta_{\text {ext }}$ and $\eta_{\mathrm{p}}$ reach $17.5 \%$ and $47.8 \mathrm{~lm} \mathrm{~W}^{-1}$ (at $59.0 \mathrm{~cd} \mathrm{~A}^{-1}$ and $0.05 \mathrm{~mA} \mathrm{~cm}^{-2}$ ), respectively. The control devices adopting BCP and BAlq as HBL showed maximum $\eta_{\text {ext }}$ of $14.5 \%$ and $\eta_{\mathrm{p}}$ of $40.0 \mathrm{~lm} \mathrm{~W}^{-1}$, and $\eta_{\text {ext }}$ of $8.1 \%$ and $\eta_{\mathrm{p}}$ of $14.2 \mathrm{~lm} \mathrm{~W} \mathrm{~m}^{-1}$, respectively, similar to the recently reported results. ${ }^{3-5}$

The reason why high quantum efficiency could be obtained from devices using DTBT as the HBL can be understood based on the energy level alignment of the layers in the devices. The lowest unoccupied molecular orbital (LUMO) levels were estimated by assuming that the HOMO-LUMO gap is equal
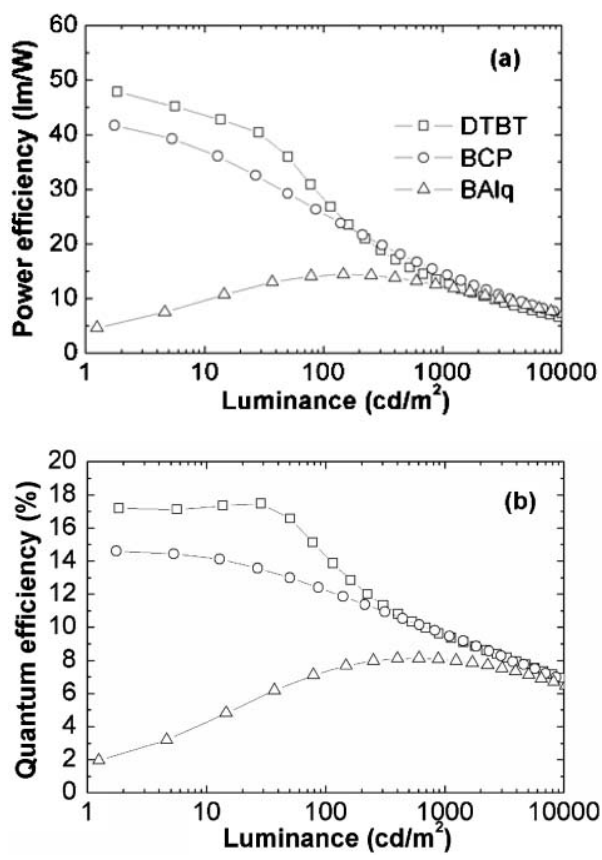

Fig. 4 (a) The power efficiency and (b) external quantum efficiency of OLEDs using 6 wt. $\% \operatorname{Ir}(\text { ppy })_{3}$ : CBP, and three different hole-blocking materials as a function of luminance.
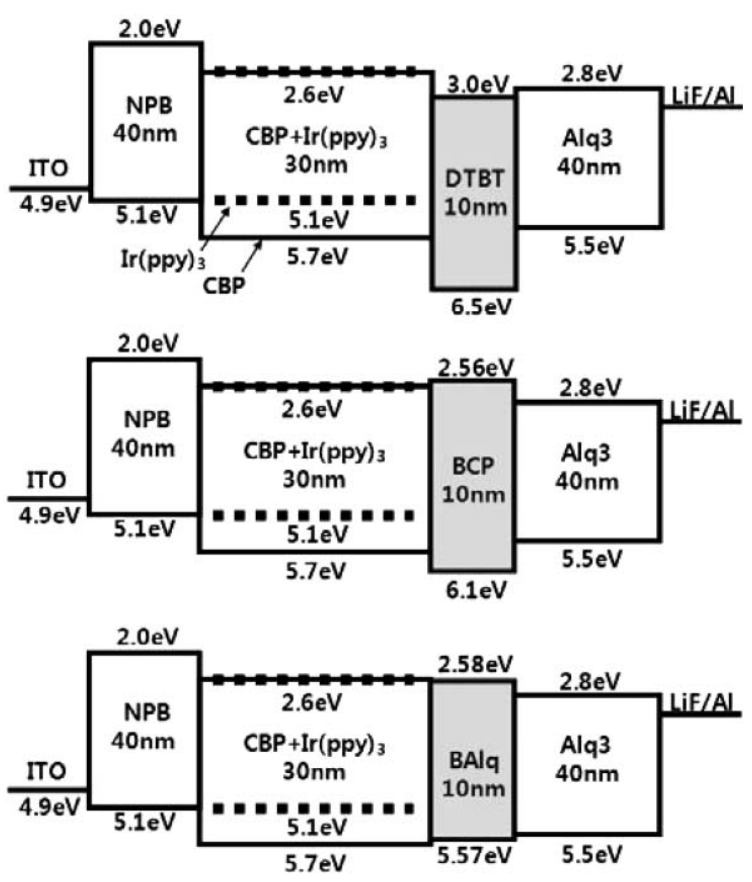

Fig. 5 Proposal energy level diagram of the electroluminescent devices (numbers represent the energy values in $\mathrm{eV}$ units).

to the optical energy gap as determined from absorption spectra. ${ }^{14}$ Fig. 5 shows a proposed energy level diagram of the electrophosphorescent device. Here we note the following reasons for the high quantum efficiency: (1) the lower HOMO level of DTBT $(6.5 \mathrm{eV})$ than those of BCP $(6.1 \mathrm{eV})$ and BAlq $(5.57 \mathrm{eV})$ leads to better confinement of holes within the EML; (2) the LUMO level of DTBT is slightly lower than those of 
$\mathrm{Alq}_{3}$ ETL and CBP, facilitating efficient electron injection from the ETL into the EML. Note that the mobility of electrons in the material is also higher than in BCP or BAlq. Therefore, the increased confinement of holes within the EML and efficient injection of electrons from the ETL explain the increased quantum efficiency of the device using DTBT as HBL.

This interpretation is also supported by the $I-V$ characteristics of the devices. The current density in the OLED using BAlq begins to increase at lower voltage than for DTBT or BCP. However the major portion of the current at voltages lower than $4 \mathrm{~V}$ in the OLED using BAlq must be hole current, manifested by the lack of light emission in the region and the low efficiency at low current density. These $I-V$ characteristics are also consistent with the lower HOMO levels, and therefore more effective hole-blocking capability, of DTBT and BCP than BAlq. Moreover the turn-on voltage of the OLED using BAlq measured at a luminance of $1 \mathrm{~cd} \mathrm{~m}^{-2}$ is higher than those of the devices using DTBT and BCP as shown in Fig. 3(b). This result indicates that the electron injection takes place at lower voltage in the devices using DTBT and BCP than in the device using BAlq, which is also consistent with the higher electron mobility of DTBT and BCP than BAlq. Lower hole leakage through the DTBT HBL than $\mathrm{BCP}$ and their similar luminance values result in higher efficiency at low current density.

It is interesting to note that the efficiency of the device using DTBT is rapidly reduced at luminances higher than $100 \mathrm{~cd} \mathrm{~m}^{-2}$. The roll-off of the efficiency in phosphorescent OLEDs has been attributed to triplet-triplet (T-T) and tripletpolaron (T-P) annihilation. Unfortunately, however, they can not explain the more rapid roll-off in the OLEDs using DTBT than using BCP. Recently we reported that the roll-off in phosphorescent OLEDs may also originate from the shift of the recombination zone to HTL. This is especially true for the roll-off at lower current density than $10 \mathrm{~mA} \mathrm{~cm}{ }^{-2} \cdot 3 a$ The high roll-off in the OLED using DTBT can be explained by the model. At low driving voltage, the recombination zone is formed near the HBL due to the higher hole mobility of NPB (order of $10^{-4} \mathrm{~cm}^{2} \mathrm{~V}^{-1} \mathrm{~s}^{-1}$ ) than the electron mobility of ETL and HBL (order of $10^{-5} \mathrm{~cm}^{2} \mathrm{~V}^{-1} \mathrm{~s}^{-1}$ ). Therefore the hole blocking capability of a HBL represented by the HOMO level dictates the efficiency at low driving voltage or low current density. With increasing current, the recombination zone shifts toward and even inside the HTL so that the efficiency is more affected by the electron blocking characteristics of a HTL at higher current density up to $10 \mathrm{~mA} \mathrm{~cm}^{-2}$. Since the same HTL of NPB was used for all the devices, we can expect the efficiency to be similar at high current density for all the devices, which is consistent with the results in Fig. 4.

The triplet energy level of DTBT $(2.44 \mathrm{eV})$ is similar to that of $\operatorname{Ir}(\mathrm{ppy})_{3}(2.42-2.46 \mathrm{eV})^{13}$ and lower than that of $\mathrm{BCP}$ $(2.5 \mathrm{eV}),{ }^{2}$ so that the $\operatorname{Ir}(\mathrm{ppy})_{3}$ triplet excitons within the emitting layer can be partially transferred to the DTBT and to a lesser extent to the BCP triplet state, and non-radiatively decay in the DTBT and BCP layers. Further improvement of quantum efficiency may be obtained if a material with high triplet energy and low HOMO level is used as the HBL.

\section{Conclusions}

We successfully synthesized a new efficient hole blocking material [DTBT] containing silane and triazine molecules for use in phosphorescent OLEDs. The material has low HOMO and LUMO levels facilitating efficient blocking of holes and transporting of electrons. As a result, the phosphorescent OLEDs fabricated using DTBT as the hole- and excitonblocking layer showed very high efficiency. A maximum external quantum efficiency of $17.5 \%$ with a maximum power efficiency of $47.8 \mathrm{~lm} \mathrm{~W}^{-1}$, which are much higher than the values obtained for BCP $\left(\eta_{\text {ext }}=14.5 \%, \eta_{\mathrm{p}}=40.0 \mathrm{~lm} \mathrm{~W}^{-1}\right)$ and BAlq $\left(\eta_{\text {ext }}=8.1 \%, \eta_{\mathrm{p}}=14.2 \mathrm{~lm} \mathrm{~W}^{-1}\right)$ as the holeblocking layer.

\section{Experimental}

\section{Synthesis of 4-bromophenyl-triphenyl silane}

To a $500 \mathrm{ml}$, three-necked flask equipped with an addition funnel and a mechanical stirrer were added dried ether $(100 \mathrm{ml})$ and 1,4-dibromobenzene (9.6 g, $0.0407 \mathrm{~mol})$. n-BuLi (26 ml, $1.6 \mathrm{M}$ in hexane) was added to the reaction mixture which was cooled to $-78{ }^{\circ} \mathrm{C}$. The reaction mixture was stirred at room temperature for $30 \mathrm{~min}$. Ether $(100 \mathrm{ml})$ solution containing dissolved triphenylsilyl chloride $(10 \mathrm{~g}, 0.034 \mathrm{~mol})$ was added to the reaction mixture slowly through the addition funnel at $-78{ }^{\circ} \mathrm{C}$. The solution was stirred at room temperature for $1 \mathrm{~h}$. The reaction mixture was poured into water and then this aqueous solution was extracted with diethyl ether. The extracts were washed with water and dried over $\mathrm{MgSO}_{4}$. The crude product was purified by silica gel chromatography using hexane to obtain a white powder. The yield was $70 \% .{ }^{1} \mathrm{H}$ NMR $\left(300 \mathrm{MHz}, \mathrm{CDCl}_{3}\right) \delta[\mathrm{ppm}]: 7.54$ (d, 8H, Ar-H), 7.43 (d, 2H, Ar-H), 7.36 (m, 9H, Ar-H).

\section{Synthesis of 4-phenylboronic acid triphenylsilane}

Dried THF (250 ml) and 4-bromotriphenylsilane [1] (8.3 g, $0.02 \mathrm{~mol}$ ) were added into a $500 \mathrm{ml}$ three-necked flask equipped with a condenser and mechanical stirrer under nitrogen. n-BuLi (20 ml, 1.6 M in hexane) was added to the reaction mixture which was cooled to $-78{ }^{\circ} \mathrm{C}$. The reaction mixture was stirred at $-78{ }^{\circ} \mathrm{C}$ for $1 \mathrm{~h}$. After lithiation, trimethyl borate $(4.2 \mathrm{~g}, 0.04 \mathrm{~mol})$ was rapidly added to the reaction mixture which was cooled to $-78{ }^{\circ} \mathrm{C}$. The solution was stirred at room temperature for $3 \mathrm{~h}$. The reaction mixture was poured into a mixture of ice and water. The mixture was acidified with $2 \mathrm{~N} \mathrm{HCl}$ and extracted with ethyl acetate, and the organic phase was washed three times with water, and dried over $\mathrm{MgSO}_{4}$. The crude product was purified by chromatography on silica gel using ethyl acetate-hexane $(1: 2)$ as the eluent to obtain a white powder. The yield was $50 \%$. ${ }^{1} \mathrm{H}$ NMR $\left(300 \mathrm{MHz}, \mathrm{CDCl}_{3}\right) \delta[\mathrm{ppm}]: 8.20(\mathrm{~d}, 2 \mathrm{H}$, Ar-H), 7.60 (d, 2H, Ar-H), 7.56 (m, 7H, Ar-H, -OH), 7.43 (m, $10 \mathrm{H}, \mathrm{Ar}-\mathrm{H})$.

\section{Synthesis of 4-bromo- $N$-benzylideneaniline}

4-Bromobenzaldehyde (22.2 g, $0.12 \mathrm{~mol})$, aniline (13.4 g, $0.144 \mathrm{~mol})$ and chloroform $(500 \mathrm{ml})$ were added into a $1 \mathrm{~L}$ 
round flask equipped with a condenser and mechanical stirrer. The reaction mixture was heated to $65{ }^{\circ} \mathrm{C}$ for $6.5 \mathrm{~h}$. After completion of the reaction, the chloroform was removed by rotary evaporator. The residual product (30 g, 96.8\%) was sufficient for the following synthetic step.

\section{Synthesis of 2-(4-bromophenyl)-4,6-diphenyl-1,3,5-triazine}

4-Bromo- $N$-benzylideneaniline $(25.9 \mathrm{~g}, 0.1 \mathrm{~mol})$ and benzamidine ( $24 \mathrm{~g}, 0.2 \mathrm{~mol})$ were dissolved in chloroform. The reaction mixture was heated to $80{ }^{\circ} \mathrm{C}$ for $24 \mathrm{~h}$. The product was precipitated by cooling to room temperature and filtered to obtain 2-(4-bromophenyl)-4,6-diphenyl-1,3,5-triazine (colorless needles). The yield was $15 \%$. ${ }^{1} \mathrm{H}$ NMR $(300 \mathrm{MHz}$, $\left.\mathrm{CDCl}_{3}\right) \delta[\mathrm{ppm}]: 8.74(\mathrm{~d}, 4 \mathrm{H}, \mathrm{Ar}-\mathrm{H}), 8.63$ (d, 2H, Ar-H), 7.64 (d, 3H, Ar-H), 7.62 (m, 5H, Ar-H). MS (ESI) (calcd for $\mathrm{C}_{21} \mathrm{H}_{14} \mathrm{~N}_{3} \mathrm{Br}$, 387.0; found, 388) $\mathrm{m} / \mathrm{z}$ : 388, 363, 338, 310, 270, 251, 236, 200, 145, 101.

\section{Synthesis of 2,4-diphenyl-6-(4' -triphenylsilanyl-biphenyl-4-yl)- 1,3,5-triazine (DTBT)}

2-(4-Bromophenyl)-4,6-diphenyl-1,3,5-triazine (5.5 g, 0.0145 mol), tetrakis(triphenylphosphine)palladium $(0)(0.08 \mathrm{~g}, 0.072 \mathrm{~mol})$, $2 \mathrm{M} \mathrm{K}_{2} \mathrm{CO}_{3}(48 \mathrm{ml})$ and toluene $(150 \mathrm{ml})$ were added to a $250 \mathrm{ml}$ three-necked flask under nitrogen. The prepared 4-phenylboronic acid triphenylsilane (4.6 g, $0.012 \mathrm{~mol}$ ) was added to the solution and heated to $110{ }^{\circ} \mathrm{C}$ for $5 \mathrm{~h}$. After cooling to room temperature, the reaction mixture was diluted with diethyl ether and organic phase was washed with water. After drying over $\mathrm{MgSO}_{4}$, the solvent was removed. The resulting crude product was passed through a flash column chromatograph to remove impurities and recrystallized from ethanol to obtain a white solid product. The yield of product was $63 \% .{ }^{1} \mathrm{H}$ NMR $\left(300 \mathrm{MHz}, \mathrm{CDCl}_{3}\right.$ ) $\delta$ [ppm]: $7.60(\mathrm{~d}, 4 \mathrm{H}, \mathrm{Ar}-\mathrm{H}), 7.54(\mathrm{~m}, 10 \mathrm{H}, \mathrm{Ar}-\mathrm{H}), 7.48$ (d, 4H, Ar-H), 7.36 (m, 13H, Ar-H), 7.22 (t, 2H, Ar-H). MS (ESI) (calcd for $\mathrm{C}_{45} \mathrm{H}_{33} \mathrm{~N}_{3} \mathrm{Si}, 643.2$; found, 644) $\mathrm{m} / \mathrm{z}$ : 644, 510, 438, 373, 360, 331, 303, 271, 259, 209.

\section{Characterization and device fabrication}

Absorption spectra of solutions were recorded with a VARIAN Cary ${ }^{\circledR} 5000$ UV-Vis spectrophotometer from 250 to $700 \mathrm{~nm}$. Photoluminance (PL) spectra were measured in a system comprising a $\mathrm{He}$ : $\mathrm{Cd} \mathrm{CW}$ laser (Melles-Griot 45MRS802-230) and a monochromator with a photomultiplier tube (Acton Research P2/PD-471). Phosphorescence spectra at $12 \mathrm{~K}$ were measured by using an ICCD camera (Princeton Instruments 7397-0005) with a Nd-YAG laser (Continuum Surelite 11-10) as an excitation source. Excitation laser power was a few tens of $\mu \mathrm{J}$, which is close to the detection limit of phosphorescence emission. Cyclic voltammetry studies were carried out with a potentiostat (Princeton Applied Research model VSP). using a three electrode cell assembly comprising $\mathrm{Ag} / \mathrm{Ag}^{+}$as the reference electrode and $\mathrm{Pt}$ as the counter and working electrodes. Measurements were carried out in $\mathrm{N}_{2}$-saturated $N, N$-dimethylformamide (for BCP and DTBT) and dichloromethane (for BAlq) solution with tetrabutylammonium hexafluorophosphate $(0.1 \mathrm{M})$ as a supporting electrolyte. Each potential was calibrated with ferrocene as a reference. The HOMO levels of BCP and DTBT were obtained from the measurement of the LUMO levels and the optical bandgaps of the materials, respectively. The detailed procedures and discussion are described in the ESI. $\uparrow$ The electron mobilities of DTBT and BAlq were measured by the time-offlight (TOF) method. The devices for the measurement consisted of a single organic layer sandwiched between two electrodes on top of a glass substrate. The bottom electrode was transparent patterned ITO with a thickness of $150 \mathrm{~nm}$. The top electrode was $100 \mathrm{~nm}$ thick Al. The thickness of the organic layer was in the range $2-5 \mu \mathrm{m}$. After deposition, all devices were sealed using glass encapsulation in $\mathrm{N}_{2}$ atmosphere. For the TOF measurements, 600 ps pulses at $337 \mathrm{~nm}$ from a nitrogen laser (USHO KEC-150) were used as optical excitation. A resistor with a value between $10 \Omega$ and $1 \mathrm{k} \Omega$ was connected in series to the samples. The photocurrent was measured with a digitizing oscilloscope (TEKTRONIX TDS3052B). All measurements were carried out at $298 \mathrm{~K}$. The electron mobility of BCP was measured by the transient electroluminescence (EL) spectroscopy method. Using a voltage pulse as an excitation source, the delay time for the EL was measured and interpreted as the electron transit time. Electron mobility was extracted by considering the luminance mechanism within the devices. ${ }^{16}$ Current densityvoltage-luminescence characteristics of OLEDs were measured with a Keithley 2400 source meter and a SpectraColorimeter PR650.

\section{Acknowledgements}

This work was supported by the Ministry of Commerce, Industry and Energy through the OLED center and Cavendish-KAIST Cooperation Program.

\section{References}

1 M. A. Baldo, S. Lamansky, P. E. Burrows, M. E. Thompson and S. R. Forrest, Appl. Phys. Lett., 1999, 75, 4.

2 V. I. Adamovich, S. R. Cordero, P. I. Djurovich, A. Tamayo, M. E. Thompson, B. W. D'Andrade and S. R. Forrest, Org. Electron., 2003, 4, 77.

3 (a) J.-W. Kang, S.-H. Lee, H.-D. Park, W.-I. Jeong, K.-M. Yoo, Y.-S. Park and J.-J. Kim, Appl. Phys. Lett., 2007, 90, 223508; (b) T. Tsutsui, M.-J. Yang, M. Yahiro, K. Nakamra, T. Watanabe, T. Tsuji, Y. Fukuda, T. Wakimoto and S. Miyaguchi, Jpn. J. Appl. Phys., 1999, 38, L1502.

4 H. J. Peng, X. L. Zhu, J. X. Sun, X. M. Yu, M. Wong and H. S. Kwok, Appl. Phys. Lett., 2006, 88, 033509.

5 M. Ikai, S. Tokito, Y. Sakamoto, T. Suzuki and Y. Taga, Appl. Phys. Lett., 2001, 79, 156.

6 C. Adachi, R. Kwong, P. Djurovichi, V. Adamovichi, M. Baldo, M. E. Thompson and S. R. Forrest, Appl. Phys. Lett., 2001, 79, 2082.

7 R. C. Kwong, M. R. Nugent, L. Michalski, T. Ngo, K. Rajan, Y.-J. Tung, M. S. Weaver, T. X. Zhou, M. Hack, M. E. Thompson, S. R. Forrest and J. J. Brown, Appl. Phys. Lett., 2002, 81, 162.

8 X. Jiang, Z. Zhang, W. Zhao, W. Zhu, B. Zhang and Z. Xu, J. Phys. D: Appl. Phys., 2000, 33, 473; C. Wang, G. Jung, Y. Hua, C. Pearson, M. R. Bryce, M. C. Petty, A. S. Batsanov, A. E. Goeta and J. A. K. Howard, Chem. Mater., 2001, 13, 1167.

9 D. Kolosov, V. Adamovichi, P. Djurovichi, M. E. Thompson and C. Adachi, J. Am. Chem. Soc., 2002, 124, 9945.

10 J. L. Kim, J. K. Kim, H. N. Cho, D. Y. Kim, C. Y. Kim and S. I. Hong, Macromolecules, 2000, 33, 5880. 
11 Y. You, C.-G. An, D.-S. Lee, J.-J. Kim and S. Y. Park, J. Mater. Chem., 2006, 16, 4706.

12 F. C. Bos and D. M. Burland, Phys. Rev. Lett., 1987, 58, 152.

13 X. Ren, J. Li, R. J. Holmes, P. I. Djurovich, S. R. Forrest and M. E. Thompson, Chem. Mater., 2004, 16, 4743; H. Inomata, K. Goushi, T. Masuko, T. Konno, T. Imai, H. Sasabe, J. J. Brown and C. Adachi, Chem. Mater., 2004, 16, 1285.
14 C.-L. Lee, R. R. Das and J.-J. Kim, Chem. Mater., 2004, 16, 4642; Y.-Y. Noh, C.-L. Lee, K. Yase and J.-J. Kim, J. Chem. Phys., 2003, 118, 2853.

15 I. Tanaka, Y. Tabata and S. Tokito, J. Appl. Phys., 2006, 99, 073501 .

16 D. J. Pinner, R. H. Friend and N. Tessler, J. Appl. Phys., 1999, 86, 5116.

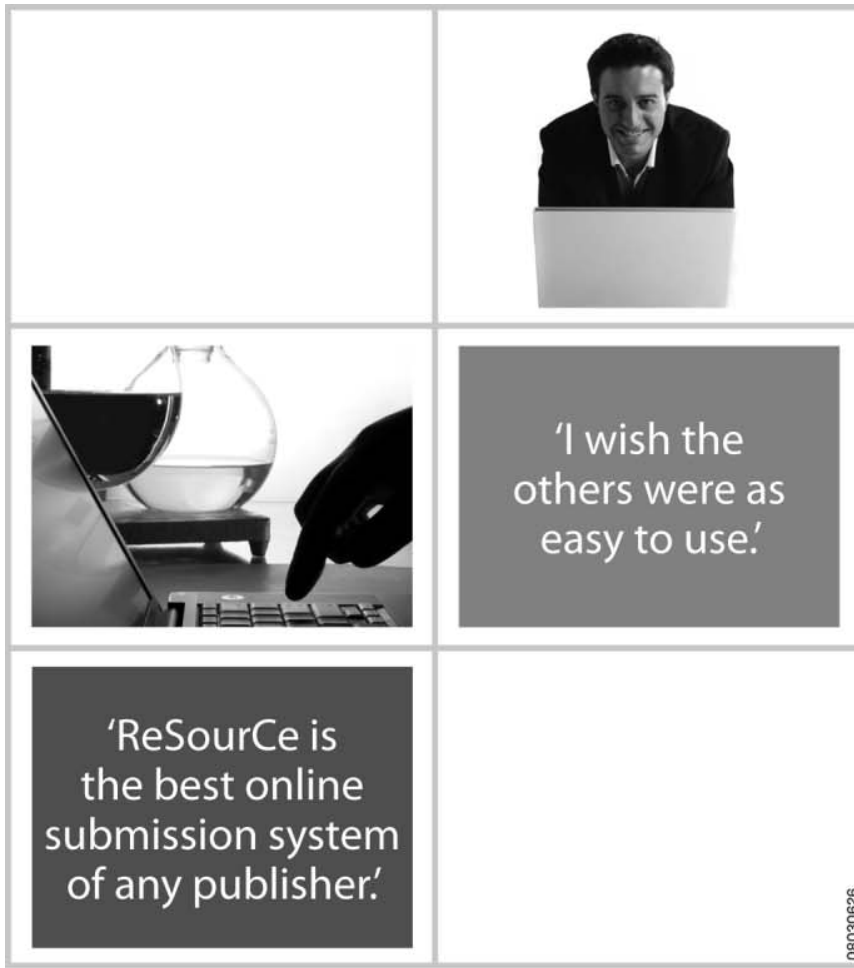

RSCPublishing
Comments received from just a few of the thousands of satisfied RSC authors and referees who have used ReSourCe - the online portal helping you through every step of the publication process.

authors benefit from a user-friendly electronic submission process, manuscript tracking facilities, online proof collection, free pdf reprints, and can review all aspects of their publishing history

referees can download articles, submit reports, monitor the outcome of reviewed manuscripts, and check and update their personal profile

NEW!! We have added a number of enhancements to ReSourCe, to improve your publishing experience even further.

New features include:

- the facility for authors to save manuscript submissions at key stages in the process (handy for those juggling a hectic research schedule)

- checklists and support notes (with useful hints, tips and reminders)

- and a fresh new look (so that you can more easily see what you have done and need to do next)

Go online today and find out more. 